\title{
ABORDAGENS E PERSPECTIVAS DE PARTICIPAÇÃO SOCIAL NO MONITORAMENTO DE POLÍTICAS PÚBLICAS
}

\author{
Leandro Antônio Grass Peixoto \\ Universidade de Brasília (UnB)
}

\begin{abstract}
ABORDAGENS E PERSPECTIVAS DE PARTICIPAÇÃO SOCIAL NO MONITORAMENTO DE POLÍTICAS PÚBLICAS
Resumo: O presente trabalho reúne algumas das recentes abordagens sobre a participação social nas etapas das políticas públicas, considerando-as em sua complexidade de atores e elementos. Evidencia especialmente a etapa do monitoramento, cujo potencial de participação social tem sido pouco debatido nas análises sobre gestão pública na contemporaneidade. Apresenta reflexões acerca do potencial participativo dos sistemas de monitoramento, contemplandoos em sua integralidade de elementos. A partir de diferentes referenciais teóricos e práticos, pretende estabelecer, aqui, uma sucinta e relevante contribuição para o campo da gestão de políticas públicas, ressaltando a participação como fundamento dos processos democráticos no século XXI.

Palavras-chave: Complexidade, ação pública, participação social, monitoramento de políticas públicas.
\end{abstract}

\section{APPROACHES AND PARTICIPATION PROSPECTS ON THE MONITORING OF SOCIAL POLICIES}

Abstract: This work brings together some of the recent approaches on social participation in public policies steps, considering them in its complexity of actors and elements. It evidences especially the stage of monitoring, whose potential for social participation has been little discussed in the analysis of public management in contemporary times. Reflections on the potential for social participation of monitoring systems, contemplating them in their entirety aspects and structures are presented. From different theoretical and practical benchmarks intended to establish here a succinct and relevant contribution to the field of public policies management, highlighting participation in support of democratic processes in the XXI century.

Key words: Complexity, public action, social participation, monitoring of public policies. 


\section{INTRODUÇÃO}

O fortalecimento da participação social nas diversas etapas que compõem o ciclo das políticas públicas tem sido amplamente debatido nas ciências sociais. $O$ entendimento de que a efetividade, a eficácia e a eficiência de uma determinada política pública relacionam-se ao nível de controle e participação exercidos sobre esta, tem ganhado destaque na abordagem de diversos autores. A noção de que as políticas públicas são mais do que iniciativas centralizadas no Estado, dotadas essencialmente de instrumentos técnicos e burocráticos, vem sendo gradualmente substituída por abordagens que convergem para uma maior complexidade e integralidade desses processos. $O$ entendimento da política como uma ação pública leva a considerar que nas iniciativas pretendidas ao tratamento dos problemas públicos encontra-se uma variedade de elementos, atores e representações a ser considerada pelos gestores.

Essa perspectiva indica uma análise complexa acerca das políticas públicas que, fundamentadas na participação, passam a caracterizar-se por uma forte dialogicidade fomentadora de cidadania. Conferências, audiências públicas, orçamento participativo e conselhos gestores exemplificam a busca pela consolidação da participação social nos diversos ciclos das políticas públicas. Especialmente na formulação, tem sido grande a relevância das contribuições da sociedade civil organizada, embora ainda haja muito que se avançar nessa etapa. Porém, outras etapas ainda apresentam certa incipiência no que diz respeito ao nível de controle e participação social, a exemplo do monitoramento.

Sendo assim, o presente artigo pretende apresentar o monitoramento como uma etapa sujeita à participação social, considerando que tal aspecto condiciona a própria dimensão participativa da política em sua integralidade. Parte-se do princípio de que a política pública, entendida como um objeto complexo, para que seja participativa, deva expressar essa dimensão em suas diferentes etapas.

Com base nas contribuições de Edgar Morin (2003), Lascoumes e Le Galés (2012) e Tenório (2013), serãoinicialmenteapresentadososelementos que sustentam o entendimento da política pública como um processo de significativa pluralidade e com potencial de promoção da cidadania se constituído em parâmetros de participação sustentados por uma razão comunicativa. Serão apresentados elementos relativos à teoria da complexidade, sociologia da ação pública e gestão social. Tais construtos teóricos visam auxiliar na compreensão do processo de participação social nas políticas públicas.

Em seguida, com base nas contribuições de Jannuzzi (2005), Silva (2005) e Tonella (2014), serão discutidos os aspectos da complexidade e da participação especificamente na etapa de monitoramento das políticas públicas. Será destacada relevância de se considerar o sistema de monitoramento dentro de sua multiplicidade de elementos, de tal forma que seu caráter participativo se revele em variáveis e instrumentos que permitam o controle social e o acompanhamento por atores sociais interessados na política.

Em suma, o presente trabalho propõe uma breve discussão que visa correlacionar as perspectivas de complexidade, diálogo e participação, constituintes da ação pública como um todo, a partir de uma de suas etapas: o monitoramento. Seu sistema, se parte integrante de uma política que se propõe fortalecer a cidadania via participação, também deve estar construído sob tal perspectiva, de forma que todos os seus elementos estejam organizados e sustentados pelas mesmas.

\section{AÇÃO PÚBLICA E COMPLEXIDADE}

Os estudos sobre políticas públicas se constituíram a partir de diferentes abordagens metodológicas e conceituais. Durante um bom tempo, grande parte delas concentrou-se no papel do Estado e em seu voluntarismo, compreendendo a política pública como uma iniciativa técnica e burocrática. O desenvolvimento do campo permitiu que as abordagens burocráticas e estatistas dividissem espaço com perspectivas que apresentam as políticas públicas como um objeto mais amplo, chamando a atenção para elementos que vão além do Estado e apontando para a relevância de outros atores.

A fragmentação analítica não representa uma exclusividade do campo das políticas públicas, mas da própria sociedade moderna, em especial da ciência. Mais do que uma demanda da própria área, a pertinência de abordagens integrais e mais amplas se apresenta como uma rota já apontada por vários pensadores, em especial Edgar Morin (2003). A denominada Teoria da Complexidade, centro das contribuições deste autor, serviu de embasamento para inúmeras abordagens nos mais variados campos do conhecimento. Na direção oposta à tradicional fragmentação científica, essa perspectiva indica a importância de um olhar holístico acerca dos fenômenos e de suas partes. Morin (2003, p. 2) justifica a relevância da complexidade tendo em vista que

[...] o princípio da separação torna-nos talvez mais lúcidos sobre uma pequena parte separada do seu contexto, mas nos torna cegos ou míopes sobre a relação entre a parte e o seu contexto.

A abordagem complexa representa uma contraposição às perspectivas lineares e fragmentadas que desconsideram a historicidade 
e a multiplicidade de atores que compõe uma determinada situação. A complexidade aplicada às ciências sociais contribui para a conexão entre as relações que constituem um determinado fenômeno da realidade. No campo das ciências sociais pode ser verificado na análise sobre a integração entre indivíduo e sociedade:

\begin{abstract}
Produzimos a sociedade que nos produz. Ao mesmo tempo, não devemos esquecer que somos não só uma pequena parte de um todo, o todo social, mas que esse todo está no interior de nós próprios, ou seja, temos as regras, a linguagem social, a cultura e normas sociais em nosso interior. Segundo este princípio, não só a parte está no todo como o todo está na parte. Isto acarreta consequências muito importantes porque, se quisermos julgar qualquer coisa, a nossa sociedade ou uma sociedade exterior, a maneira mais ingênua de o fazer é crer (pensar) que temos o ponto de vista verdadeiro e objetivo da sociedade, porque ignoramos que somos uma pequena parte da sociedade. Esta concepção d e pensamento dá-nos uma lição de prudência, de método e de modéstia. (MORIN, 2003, p. 5).
\end{abstract}

Uma das abordagens das ciências sociais que se relaciona com a teoria da complexidade é a Sociologia da Ação Pública. Desenvolvida pelos franceses Pierre Lascoumes e Patrick Le Galés (2012), a concepção das políticas públicas como um processo que engloba múltiplos atores e aspectos, para além do Estado e sua burocracia, vem ganhando destaque. Rompendo com o voluntarismo político e a unicidade estatal, esta abordagem apresenta as interações entre diferentes atores e instituições como elemento central na análise das políticas. Trata-se de entender a política pública como uma iniciativa coordenada que visa à realização de objetivos comuns associados ao enfrentamento do problema público.

Nessa linha, a ação pública é compreendida a partir de cinco elementos, que segundo Lascoumes e Le Galés (2012), constituem o pentágono da política pública: atores, instituições, representações processos e resultados (Figura 1). Os atores, sejam individuais ou coletivos, são guiados por interesses e fazem escolhas segundo os recursos que possuem. As representações "[...] são os espaços cognitivos que dão sentido às suas ações, as condicionam e as refletem." (LASCOUMES; LE GALÉS, 2012, p. 44). Os atores interagem por meio das instituições, que normatizam e criam uma rotina para os processos. Por fim, os resultados refletem as consequências da ação pública e desse conjunto de interações.

Os mesmos autores relacionam o fracasso das políticas públicas, especialmente em sua implementação, às fragilidades que o modelo top down apresenta por desconsiderar as dinâmicas sociais existentes no contexto. Tal fracasso, interpretado a partir da inefetividade, ineficiência e da ineficácia, associa-se a essa desconsideração da complexidade das políticas, sendo este um fator significativo para que as ciências sociais

Figura 1- Pentágono das políticas públicas

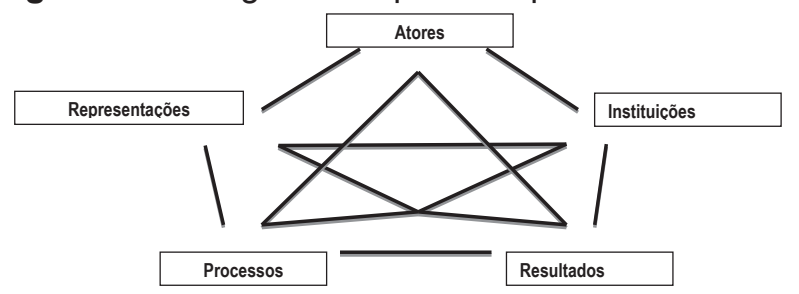

Fonte: LASCOUMES, Pierre; LE GALÈS, Patrick. Sociologie de l'action publique: domaines et approches. 2. ed. Paris: Armand Colin, 2012. P. 45.

desenvolvam novas abordagens acerca do tema. Mais adiante, tais aspectos, em especial o da eficiência, serão analisados dentro do processo de monitoramento. Portanto, a consideração da política pública como um fenômeno dinâmico e complexo passa a vigorar, rompendo com a tradição de análise centrada no Estado e em sua burocracia, de forma a admitir a existência de outros fatores, especialmente os que evidenciam a participação de diferentes atores sociais.

\section{ESTADO, CIDADANIA E GESTÃO SOCIAL}

A abordagem da Sociologia da Ação Pública, apoiada e combinada com a teoria da complexidade, indica a relevância do papel dos atores sociais e suas representações nas diferentes etapas das políticas públicas. O seu posicionamento nas etapas da política, em especial no monitoramento, conduz à reflexão acerca das condições de participação social e de uma nova relação Estado-sociedade. A perspectiva clássica e tradicional das políticas públicas, em sua verticalidade analítica, combinada com teorias modernas da administração, fortaleceu a noção de gestão como uma iniciativa técnica e burocrática. No entanto, recentes experiências e abordagens destacam uma nova concepção de gestão, sustentada pela participação intensa da sociedade civil organizada nas diversas etapas das políticas públicas. Trata-se da concepção de gestão social.

A gestão social pressupõe o diálogo nos processos constituintes da ação pública que, rompendo com a instrumentalidade - em especial por parte do Estado - das políticas, se constrói mediante um processo que viabiliza simultaneamente a emancipação via participação. Inspirada nas análises e abordagens da Escola da Frankfurt, a noção de gestão social se contrapõe a de gestão estratégica (TENÓRIO, 2013). Essa dicotomia se 
estabelece em parâmetros que estão associados ao sentido da razão, tal como sustentado na crítica dos frankfurtianos, contrapondo razão instrumental e razão comunicativa.

$\mathrm{Na}$ gestão estratégica, os sistemas de políticas públicas

[...] são configurados e orientados segundo os princípios da razão técnica (instrumental), a qual chega a identificar-se com a razão política ou até com a razão de uma maneira geral. (TENÓRIO, 2013, p. 15).

Nesse contexto, todo o modelo políticoinstitucional se adequa a essa lógica que, orientada pela instrumentalidade, nega as dimensões subjetivas do processo, em especial a ideológica. Desta forma, a contraposição entre as duas perspectivas reside justamente no fato de que

\begin{abstract}
[...] enquanto no processo de gestão estratégica, harmônico com o agir estratégico, monológico, uma pessoa atua sobre a outra(s) para influenciar a continuação intencional de uma interação (neste tipo de ação a linguagem é utilizada apenas como meio para transmitir informações), sob uma ação comunicativa, dialógica, um indivíduo procura motivar racionalmente outro(s) para que este concorde com sua proposição (neste tipo de ação a linguagem atua como fonte de interação social). (TENÓRIO, 2013, p. 17).
\end{abstract}

A oposição entre esses dois modelos se apresenta também nos formatos dos processos decisórios. A gestão social pretende a substituição de uma relação unilateral e vertical por processos mais dialógicos, capazes de oportunizar a intervenção dos diferentes atores sociais. Orientada por uma racionalidade comunicativa, a gestão social pressupõe a contemplação das diferentes representatividades e, sem impor suas aspirações, busca estabelecer decisões coletivas a partir da escuta das diferentes expressões. Estas, expressadas e compreendidas racionalmente, tendem a contribuir para o estabelecimento de uma legitimidade em torno da ação pública e potencializar sua eficácia.

A gestão social, orientada por uma ação gerencial dialógica contempladora das diferentes representações e atores sociais, viabiliza a emergência do que se compreende como cidadania deliberativa (TENÓRIO, 2013). Trata-se de uma nova modelagem da interação Estado-sociedade, permitindo que os cidadãos tenham acesso a instrumentos de controle sobre as políticas públicas. Nesse processo, o indivíduo
[...] ao tomar ciência de sua função como sujeito social e não adjunto, ou seja, tendo conhecimento da substância social de seu papel na organização da sociedade, deve atuar não somente como contribuinte, eleitor, mas como uma presença ativa e solidária nos destinos de sua comunidade. (TENÓRIO, 2013, p. 19).

Nesse contexto, a interação dos diferentes atores deve ser compreendida a partir de uma contextualização que permita estabelecer a relação existente entre o problema público e os sujeitos envolvidos, bem como a carga representativa e simbólica que cada grupo ou indivíduo traz consigo. Nesse sentido, é fundamental considerar a dimensão política dos problemas públicos. As arenas das ações públicas são carregadas de representações que ultrapassam a objetividade, dotando-as de um pluralismo, o qual deve ser levando em conta não tão somente pelo corpo gestor, mas também pelos demais atores da ação pública. Uma vez que a própria sociedade se faz representada no processo da ação pública, os atores apresentarão as características do universo social em que se inserem:

Um equívoco é analisar o polo sociedade
como homogêneo, desconsiderando que
este apresenta práticas e concepções
heterogêneas e está atravessado por
interesses e tensões. São múltiplos os
sujeitos, tanto do campo progressista
quanto do campo conservador, que
se manifestam também em espaços
diversos e multifacetados. São
associações de classe, sindicatos de
trabalhadores e patronais, conselhos,
fóruns, redes de movimentos vinculados
a lutas especializadas (como bairros ou
conjuntos habitacionais) ou temáticos
(como mulheres, negros). (TONELLA,
2013, p. 39).

Considerado a pluraridade histórica e representativa dos atores e instituições de uma ação pública, esta passa a ser entendida não mais como um empreendimento técnico e burocrático, caracterizado pela centralidade dos processos decisórios, mas sim como um processo que se orienta por um construtivismo moderado (TONELLA, 2013). A gestão da política se estabelece a partir de um sistema de ordem negociada, cujo sucesso está diretamente associado às possibilidades de manifestação dos diferentes atores.

No entanto, tal como será apresentado adiante, as possibilidades de participação social não necessariamente se limitam apenas às etapas iniciais da política pública, mas podem ocorrer nas demais. Especialmente no Brasil, tem-se apresentado uma variedade de estudos e experiências que indicam possibilidades de 
participação social no planejamento, execução, avaliação e, especialmente, no monitoramento das políticas públicas. São, portanto, ilustrações das noções até aqui representadas, indicando que uma visão sistêmica e complexa da ação pública permite o reconhecimento de aspectos e atores que ultrapassam a dimensão do Estado e fortalece a participação, potencializando a legitimidade democrática das políticas.

\section{PARTICIPAÇÃOSOCIALNOMONITORAMENTO DAS POLÍTICAS PÚBLICAS}

A consolidação da participação social na gestão das políticas públicas ainda apresenta inúmeros desafios. Embora tenha ocorrido um significativo avanço nos processos de organização e formalização das esferas de participação, como as conferências e os conselhos populares, nota-se que ainda há uma série de demandas relativas ao efetivo controle social nas diversas etapas das políticas. Os conselhos de gestão, em seu caráter essencialmente consultivo, muito têm contribuído para a estruturação de programas, mas ainda há lacunas da participação social nas demais etapas que compõem a política. $E$ uma delas é o monitoramento, que por vezes não apresenta instrumentos viáveis para um efetivo controle social.

As perspectivas de gestão pública do século $X X I$ avançaram no que diz respeito à transparência, comunicação aproximação entre Estado com sociedade civil. O caráter participativo das democracias vem sendo incrementado a partir de diversas experiências que visam legitimar as políticas públicas e romper com o voluntarismo estatal. Trata-se em de uma ruptura justificada por argumentos que tangem a própria essência do processo democrático, como apresentado por Ciavatta (2002, p. 91):

Se as estratégias de decisão política não ultrapassarem os mecanismos formais da participação pelo voto e de eleição de representantes, e não incorporarem as demandas formais do conjunto dos cidadãos, o jogo democrático se converte num mero formalismo. O regime democrático representativo torna-se um simulacro útil às dominações oligárquicas que, na história constitucional de nossos povos, sempre foram tão excludentes quanto repressivas.

Apresenta-se, aqui, portanto, uma discussão central acerca da dimensão participativa na integralidade das políticas. Compreender a ação pública em sua complexidade, percebendo-a como um processo que contempla variados aspectos e atores, implica também na criação de mecanismos que sustentem as conexões de forma efetiva, e não apenas simbólica. A ruptura com o centralismo do Estado deve viabilizar canais que permitam à sociedade civil organizada participar de forma racional e consciente, compreendendo e significando processos e instrumentos constituintes da política. Este representa um dos desafios centrais na gestão das políticas públicas:

A questão central que as estratégias de participação e controle social colocam para a gestão é como proceder à melhor tradução possível das demandas da sociedade, expressas nos documentos finais das conferências - sejam eles relatórios, diretrizes, ou resoluções - em políticas concretas, ajustes e aprimoramentos dessas políticas. A escolha de estratégias, metodologias e instrumentos de gestão a serem utilizados em todo o ciclo da política (planejamento, implementação, monitoramento e avaliação) deve levar em conta argumentos de razoabilidade $\mathrm{e}$ eficiência gerencial ou técnica, que são compatíveis com os critérios democráticos de responsabilização dos agentes estatais (organizações e indivíduos), transparência e garantia de participação e controle social. (BRANDT; BEZERRA, 2013, p. 10).

A participação social no monitoramento das políticas públicas tem como um de seus principais entraves a compreensão dos aspectos que constituem essa etapa por parte dos diversos atores sociais. Fazse então necessário que os instrumentos constituintes do sistema de monitoramento sejam inteligíveis e acessíveis às categorias sociais interessadas na determinada política. É preciso considerar que o monitoramento, assim como a formulação da política, também representa uma possibilidade de participação e controle social, não sendo apenas de interesse do corpo técnico-burocrático dos órgãos gestores. Isso se deve ao fato de que

[...] o contexto do sistema de monitoramento pode ser representado por organizações governamentais que atuem nas diferentes esferas de governo ou por organizações não governamentais. Quanto aos agentes sociais envolvidos no desenvolvimento e implementação do sistema de monitoramento, estes podem ser representantes da comunidade, agentes implementadores dos programas e agências de pesquisa públicas ou 
privadas, tendo em conta que estas características não são excludentes entre si. (SILVA, 2005, p.122)

Assim como os documentos resultantes das deliberações populares acerca das políticas públicas devem ser acessíveis e compreendidos pelos gestores públicos, o mesmo vale para os sistemas de monitoramento em relação à sociedade civil. Tratando-se de um construto analítico, rico em elementos técnicos de ordem estatística, a inteligibilidade dos indicadores de um sistema de monitoramento certamente representa um dos grandes entraves para o controle social. Além de seu caráter estatístico e matemático, por vezes os indicadores também carregam fortes traços técnicos em sua própria descrição, fato que potencializa os obstáculos para grupos que têm interesse no monitoramento, mas que, devido aos pré-requisitos interpretativos, não se habilitam para participar nessa etapa.

A dificuldade no acesso ao sistema de monitoramento reflete os elementos apresentados anteriormente e referentes à lógica racional predominante nos processos de gestão estratégico. Por vezes, a inacessível linguagem técnica na própria descrição dos indicadores reflete uma expressão de poder simbólico, traço da racionalidade instrumental que rompe com ação comunicativa e bloqueia a emancipação. Os indicadores devem, portanto, ser elaborados contemplando as possibilidades de acesso e participação por parte dos grupos interessados na política e permitindo que o próprio sistema de monitoramento se torne um instrumento de participação e controle social. Nesse sentido, o próprio corpo gestor que concebe o sistema deve estar imbuído da perspectiva complexa e dialógica:

Para o efetivo monitoramento e avaliação das políticas em geral, os gestores precisaram aprender a escrever enunciados claros para as ações, que permitam a compreensão de seus objetivos, a referência a públicosalvo, bem como metas e indicadores consistentes [...] Nesse contexto, há que se refinar o debate em torno de indicadores - quais suas qualidades necessárias e, principalmente, a associação estrita com a construção de dados estatísticos primários que os alimentem. A construção de indicadores que meçam o movimento de gradientes de raça/cor ou gênero nos diversos campos é complexa, mas não impossível. (BRANDT; BEZERRA, 2013, p. 18).

Considerar as contribuições da sociedade civil e a participação social nas diversas etapas constituintes do ciclo das políticas públicas tende a servir para a própria qualificação das ações. Não apenas em sua dimensão qualitativa - de promoção da cidadania - mas também nos resultados quantitativos, uma política tende a ser impactada positivamente pelo fortalecimento do controle social. Por vezes a centralidade e o voluntarismo, inclusive no monitoramento, podem sustentar uma noção de efetividade/eficiência/eficácia que não corresponde, de fato, aos aspectos fundamentais do problema público.

Isso se justifica pelo fato de que, embora o Estado tenha condições e recursos para identificar e compreender os variados elementos de uma determinada realidade na qual se implementa uma política, os atores sociais, cotidianamente confrontados pelo problema, possuem significativa legitimidade para interpretar os impactos e as mudanças que ali ocorrem. Nesse sentido, vale destacar que a plenitude do sistema de monitoramento passa, fundamentalmente, pela escuta e participação destes atores, uma vez que nem sempre os indicadores por si sós serão capazes de expressar a efetividade da política. Sendo assim,

[...] a opinião da população atendida por um programa é certamente importante, desejável e complementar em qualquer sistemática de monitoramento e avaliação, trazendo subsídios para a correção e melhoria do processo de implementação dos programas e também indícios da efetividade social desses programas, especialmente aqueles difíceis de serem mensurados em uma escala quantitativa. (JANNUZZI, 2005, p. 144).

Retoma-se aqui a importância sobre a abordagem da complexidade no estabelecimento de uma ação pública dialógica. As diversas variáveis que compõem o sistema de monitoramento devem permitir que a participação se estabeleça (Quadro 1). Dado o enfoque na dimensão dos indicadores, Silva (2005) aponta também para uma concepção integral do sistema de monitoramento, de forma que o controle social e o diálogo se estabeleçam em todas as variáveis de operacionalização desse sistema. Nesta concepção, além de se contemplar os próprios atores sociais como uma variável, o caráter participativo do sistema se expressa nos demais elementos, desde os objetivos e conceitos, passando pelas metodologias e níveis de análise até o próprio processo de publicização desse sistema. Em todos eles a perspectiva participativa deve ser 
contemplada, de forma a permitir efetivamente um sistema de monitoramento aberto ao controle social.

Quadro 1 - Variáveis de operacionalização do sistema de monitoramento

\begin{tabular}{|ll|}
\hline 1. & Objetivo geral \\
\hline 2. & Objetivos específicos \\
\hline 3. & Conceitos \\
\hline 4. & Metodologia \\
\hline 5. & Nível de análise \\
\hline 6. & Contexto \\
\hline 7. & Atores sociais envolvidos \\
\hline 8. & Publicização \\
\hline Fonte: SILVA, Maria de Fátima. Modelo de referência para análise \\
e desenvolvimento de sistemas de monitoramento \\
de intervenções de governos municipais no campo \\
habitacional. 2005. 382 f. Tese (Doutorado em Engenharia \\
de Produção) - Universidade Federal de Santa Catarina,
\end{tabular}

Por fim, nesse contexto emerge a questão acerca das condições que, se não pré-existentes, devem ser dadas para que os grupos e atores se tornem capazes de participar ativamente do monitoramento. As instituições responsáveis pelas políticas devem agir como espaços de facilitação, tomando a comunicação como princípio na estruturação do sistema de monitoramento. À medida que isso se torna cada vez mais recorrente, agrega-se eficiência na política, uma vez que vão sendo potencializados os grupos de interesse e demais atores sociais quanto ao domínio conceitual, programático e técnico da política. $\mathrm{O}$ incentivo à participação também se apresenta como um elemento determinante. É preciso que a população sinta-se parte e perceba os benefícios desse processo, tomando os resultados da política como causa e consequência de seu próprio desenvolvimento. Retoma-se, aqui, a ideia de que a dimensão participativa tende a refletir no próprio sucesso da política, tendo em vista que a

[...] eficiência depende do acúmulo de experiência da ação coletiva, por parte da população, que permita a formação de capital social local e da existência de formatos institucionais adequados que capacitem os grupos para o debate, formulação de propostas e a criação de incentivos seletivos à participação. (SILVA, 2005, p. 197).

Desta forma, pensar um sistema de sistema de monitoramento que se integre a uma concepção complexa de participação social implica necessariamente em pensar este sistema de forma complexa e dialógica. É preciso que seus elementos estejam apoiados em uma racionalidade comunicativa, que não sendo apenas inteligível e acessível, também sirva como base de participação e controle social.

\section{CONCLUSÃo}

Acondiçãodoconhecimentonamodernidadese estabeleceu dentro de uma perspectiva fragmentada e essencialmente linear. Tal característica ainda na contemporaneidade se expressa não tão somente na própria construção dos saberes, mas também em sua aplicação. Entre as alternativas de ruptura dessa noção acerca do conhecimento, encontra-se a teoria da complexidade. Enquanto uma proposta científica de dissociação com esta tendência, esta vem sendo cada vez mais apropriada por diversos campos analíticos e práticos, entre eles as políticas públicas. As abordagens mais recentes do campo apontam para um entendimento mais integral das ações do Estado, dissociando-as de uma centralidade e percebendo-as como uma ação que se relaciona a outros atores e instituições. Constrói-se então a perspectiva da ação pública.

Nessa perspectiva a resolução dos problemas públicos passa pela interação entre diversos elementos que, combinados e considerados, tendem a se refletir no próprio sucesso das políticas públicas. Considerar a ação pública como um processo integral e dialógico implica, consequentemente, no fortalecimento da dimensão participativa dos atores sociais, capazes de exercer controle desde a formulação até a avaliação das políticas públicas.

Muitos são os desafios que se apresentam na consolidação dessa participação nas diversas etapas que compõem o ciclo das políticas públicas. Entre eles, vale destacar os que estão associados à participação no monitoramento das políticas, predominantemente sistematizado sob uma perspectiva técnica e instrumental. Experiências e pesquisas de processos de gestão têm apontado para alguns aspectos que merecem atenção no fortalecimento da dimensão participativa do sistema de monitoramento. Entre eles destaca-se a relevância de um conjunto de indicadores que sejam acessíveis e inteligíveis aos atores interessados na política, além de um sistema que, como um todo, esteja sustentado dentro de uma razão dialógica em suas diversas variáveis.

Pensar as políticas públicas como processos complexos e dialógicos implica, consequentemente, em estabelecer em suas etapas estes mesmos princípios. No caso do sistema de monitoramento, uma vez que este se constitui como parte de um objeto que se pretende a ser controlado e passível de participação, também deve estar constituído dentro da mesma perspectiva. Em suma, uma política pública que permita a participação deve estar construída sobre processos, instrumentos e instituições que sejam essencialmente participativos. 


\section{REFERÊNCIAS}

BRANDT, Maria Elisa Almeida; BEZERRA, Carla de Paiva. A participação e o controle social nas políticas para as mulheres: desafios postos para a gestão pública. In: CONGRESSO CONSAD DE GESTÃO PÚBLICA, 6., 2013, Brasília, DF. Anais ... Brasília, DF: CONSAD, 2013.

CIAVATTA, Maria. A construção da democracia pós-ditadura militar: políticas e planos educacionais no Brasil - democracia e construção do público no pensamento educacional brasileiro. Petrópolis: Vozes, 2002. p. 68-86.

JANNUZZI, Paulo de Martino. Indicadores para diagnóstico, monitoramento e avaliação de programas sociais no Brasil. Revista do Serviço Público, Brasília, DF, v. 56, n. 2, p. 137-160, 2005.

LASCOUMES, Pierre; LE GALÈS, Patrick. Sociologie de l'action publique: domaines et approches. 2. ed. Paris: Armand Colin, 2012.

MORIN, Edgar. Da necessidade de um pensamento complexo. In: MARTINS, Francisco Menezes; SAILVA, Juremir Machado da (Orgs.). Para navegar no século XXI: tecnologias do imaginário e cibercultura. 3. ed. Porto Alegre: Sulina/Edipucrs, 2003. p. 13-36.

SILVA, Maria de Fátima. Modelo de referência para análise e desenvolvimento de sistemas de monitoramento de intervenções de governos municipais no campo habitacional. 2005. 382 f. Tese (Doutorado em Engenharia de Produção) - Universidade Federal de Santa Catarina, Florianópolis. 2005.

TENÓRIO, Fernando Guilherme. Gestão social: uma perspectiva conceitual. Revista de administração pública, v. 32, n. 5, p. 7 a 23, 2013.

TONELLA, Celene. Políticas urbanas no Brasil: marcos legais, sujeitos e instituições. Sociedade e Estado, Brasília, DF, v. 28, n. 1, p. 29-52, jan./abr. 2013.

\footnotetext{
Leandro Antônio Grass Peixoto

Sociólogo

Doutorando do Programa de Pós-Graduação em Desenvolvimento, Sociedade e Cooperação Internacional do Centro de Estudos Avançados Multidisciplinares (CEAM) da Universidade de Brasília (UnB)

E-mail: leandrograss@gmail.com
}

Universidade de Brasília - UnB

Campus Universitário Darcy Ribeiro, Brasília - DF

CEP: $70910-900$ 